\title{
Perception of Visual Impairment Towards the Aesthetic of Architectural Elements
}

\author{
Komang Ayu Laksmi Harshinta Sari, Arina Hayati, and FX Teddy Badai Samodra \\ Department of Architecture, Institut Teknologi Sepuluh Nopember, Surabaya \\ e-mail: arina_h@arch.it.ac.id
}

\begin{abstract}
Abstrak-Phenomenology in architecture is associated with perception between the subject and the space, which one of the studies includes multisensory experience. In general, contemporary architecture accentuates the visual experience, among other sensory modalities. Therefore, it is necessary to conduct research about the exploration of multisensory perception in architectural design. This study aims to explore how sensory activities or blind and visual impaired experience the spatial and the elements of architecture. This study is started by examining a brief literature review and then conducts qualitative research (in-depth interview and participant observation) to explore sensory experience and perception of blind people. The result finds from the five elements, walls and windows are the most influential elements for blind people. The existence of a wall has the potential to be a wayfinding of haptic system and has an echo effect. While the aperture opening element influences the illumination of light as well as indicators of outside space limits. The research outcome shows that people with visual impairment also acknowledge and they recognize these principles of design. They recognize contrast of temperature through the opening element, rhythm of texture through the wall, surface balance through the furniture, and hierarchy of noise through the window.
\end{abstract}

Kata Kunci-Sensory Experience, Blind People, Design Communication.

\section{INTRODUCTION}

$\mathrm{T}$ HE abundance of human sensory system has encouraged the architects to further analyze multisensory architecture. A critique that discussed by Pallasma (2005) will urge the architecture practitioner to consider the integration of human perception system to create quality of multisensory space without dominating visual perception [12]. An architectural object has deep connection with its user perception; therefore, Vermeersch stated that multisensory architecture expands more spatial experience rather than visual-prioritized architecture [16]. According to Gibson, Perceptual system itself consists of auditory system, haptics, visual system, and basic oriented system [7]. Based on those several perceptual systems, architecture design involving all the human sensory system provides new knowledge and experience for all users.

Architecture will be more interesting if other perceptual systems contribute to design exploration instead of accentuate visual perception solely. This design approach not only explores how people experience and interact with their built environment but also to understand how people have different perception of architectural experience with their senses beside visual. As a result, to comprehend 'What is architecture?' with emphasizing non-visual perception, this research focuses on people with vision disabilities. For people with visual impairment who used to focus on visual panorama will adjust their attention to accept stimulus from other sensory. This statemtnt is in line with Hill (1985) that visual impaired people utilize their multisensory to learn and acknowledge the environment [5]. According to Pereire in Vermeersch (2010) as a person with loss of vision since 2006 stated that being blind made other senses beside visual will be well developed [15].

In general, Pallasma in Sabatini et al (2017) stated that the absence of soul in contemporary architecture results in lack of experience towards the users. Pallasmaa also explained that architecture is not only a knowledge about understanding the art of making human dwelling, but also it has other purposes such as metaphysical and mental experience. Majerova (2017) described how perception from participant with visual impairment has impact on their environment [9]. When visual modality is no longer working properly, then other senses (such as smell, touch, taste, hearing) and imagination become important stimulus receptor. Gathered information create new images, words, and other new perception; a new mental representation in general. Sensation and perception create basic terms for imagination [9]. To find and understand the environment, people with loss of vision collect information through their haptic system. In this case, they are able to perceive volume, outline, and surface of a space with their own practical and sensitive ways [2].

This research examines perception from people with visual impairment, with productive age range and have educational background, towards the aesthetic of architectural building. Through certain criteria, these participants influence exploration of new experience supported by Pallasmaa's theory (2005) along with similar research findings from Vermeerch (2010). Many previous studies also related topic about visual impairment such as Jenkins (2015), Mcintyre (2014), and Hill (1985). The first one discussed multisensory experience of people with visual disability through barriers, supporters, and context-dependence [6]. The second research described the experience from people with visual impairment during navigating general function buildings related to existing building regulation [10]. Hill (1985) Visual impairment are able to solve spatially-based, environmental problems without visual cues, blind individuals demonstrate 
The $6^{\text {th }}$ International Seminar on Science and Technology (ISST) 2020

July $25^{\text {th }} 2020$, Institut Teknologi Sepuluh Nopember, Surabaya, Indonesia

Table 1.

of participant and type of visual impairment

\begin{tabular}{|c|c|c|c|c|}
\hline No. & Name & Type of Visual Impairment & Age & Occupation \\
\hline 1 & Egar & Totally Blind (since 3th grade) & 23 & Student \\
\hline 2 & Ade & Totally Blind (since 13 years old) & 23 & Student \\
\hline 3 & Fajar & Totally Blind (since 8 years old) & 23 & Student \\
\hline 4 & Wawa & Low Vision (since 10 yeas old) & 25 & Student \\
\hline 5 & Didi & Low Vision (since elementary) & 23 & Student \\
\hline
\end{tabular}

that sight is not absolutely necessary for orientation and wayfinding [5]. Viewing the human situation in such a way provides a "seeing of the world" based on non-visual bonds. Without sight, the other senses reach out to a world and draw closer to it, thereby coming to know these other dimensions of the world more intimately.

Pallasmaa (2005) on chapter 2 from the book 'The Eye of Skin' discussed senses interaction gives personal impression in order to express architectural experience with the help of multisensory experience [12]. Among others are significance of the shadow, acoustic intimacy, Silence, Spaces of scents, the shape of touch, Space of memory and imagination and an architecture of the senses [12]. Those reviews contribute to support the answers from visual impaired participant towards acknowledging surroundings.

The discussion of this study is also related to the aesthetic principle of space and physical elements perceived by the blind..Architecture design principles such as unity and its components, proportion, hierarchy, symmetry, differential, balance, repetition, alternation, contrast, and rhythm, have their isomorphic in music, paintings, language and literature, math, biology, physic, and psychology [4].Those principles in general can be experienced through visual system, therefore, these participants are visually impaired so those principles is helpful to analyze aesthetic architectural elements through perception of participants that appear to be more sensitive.

\section{METHODOLOGY}

Research method based on phenomenology commonly analyzes designer's perception on creating space for people that include their environment and buildings. Phenomenology is a qualitative method based on the philosophy of phenomenology. The qualitative researchers study hands-on experiences of human beings, events, and their meanings to find precise explanations, explore overlooked aspects and identify its practical implications [8]. This will create reciprocity between buildings and the site, or human and nature. From this phenomenon, it will result different person's perspective that capture new experience. Life experience itself can be gathered from various ways. As believed by Van Manen, the way to collect life experience includes describing, assembling, interviewing, observing experience, and reporting both fiction and imaginary experiences [8].

Juhani Palassma in Tran (2018) developed himself emotionally towards self-sensory, in his infamous artwork, The Eye of Skin. He encountered that the world is not only see but also hear, smell, taste, and touch [14]. Therefore, this research collected five participants as respondent that experienced different visual impairment including partially and totally blind. In relation to the creativity and training center for visual impairment design, choosing respondents will focus on productive age. Private information including name and schools will be protected and using pseudonym instead.

Various type of blindness will diversify the perception of people with loss of vision against quality of space. This research includes three participants with total blind and two with partial blind or low vision. Those five participants were interviewed partially one-on-one and the rest through social media messaging. The interview session is open which means has no limit to the result and be able to develop based on participant's point of view and experience. The questions that has submitted are stated below.

1. Which sense is the most delicate in order to recognize a space?

2. Could you describe an experience about space or architecture that impressed you the most based on your perception?

3. What is your perception towards the aesthetic of a building that involves quality of noise, textures, lighting, and airflow?.

Participant and type of visual impairment can see Table 1.

\section{RESULT AND DISCUSSION}

Rapoport Theory (1982) became basic reference in terms of deciding building elements that will be discussed. It divided element into three types; fixed element, semi element, and non-fixed element [13]. The first classification that will be used is fixed element, which means this element is permanent and cannot be replaced. This research also cover exploration of wall, aperture, railing, and paving blocks, which related to visual impairment's perception whereas furniture element will be considered as semi fixed element. This result and discussion will influence the quality of space that created from visual perception towards building elements (the user's mobilization and coziness). Also design communication from the blind perception of the aesthetics of building elements.

\section{A. Wall}

Pallasma (2005) stated that buildings do not react to our gaze, but they resonate sound to our ear [12]. The echoes that come from our footsteps on asphalt road make people feel emotional because the echoes from the surrounding walls make direct interaction to the space itself; sounds measure the space and make its scale acknowledged. Beside with the help of sound, skin can also recognize textures, weight, mass, and temperature of certain element. One stated that skin could 
The $6^{\text {th }}$ International Seminar on Science and Technology (ISST) 2020

July $25^{\text {th }} 2020$, Institut Teknologi Sepuluh Nopember, Surabaya, Indonesia

identify room temperature precisely, breeze under the tree or warmth under the sun, transform into experience against space and environment.

People with visual disabilities can distinguish dimension and characteristic of a space based on sound, echo, vibration, and wind. However, other user or inhabitant usually disobey this perceptual sign[3]. Pereira on Vermeersch (2010) stated the idea of aesthetic in general still rely on visual aspects [15]. Pereira is a young architect that lost his sight due to accident a few years ago [15]. This certainly changed his stigma of perception towards architecture. According to his view, there are many things in spatial placement come in unpleasant form and texture, including acute shape in some areas. Therefore, he favors choosing ergonomic geometry or safety matter [15].

Those explanations are aligned with perception participant with visual impairment against wall element. This element can help some individuals to recognize the area of the space through its reflection. The total-blind participants can distinguish how narrow and wide of a certain area through contrast of temperature. If the temperature is high, then they can assume that space is narrow or cramped. In contrast, they suppose that space is wide and big if the temperature is low or colder. "Determine how small and confined an area through echo, temperature; if the space is big then the echo is more reverberating, if it's narrow then it muffled." Fajar, 23 years old said. Placement of ornament rhythm or furniture on the wall certainly helps to divine path for participants. Switching textures through ornament on the wall often become indication of a space. On the other hand, choosing ornament's surface and wall decoration should not harm people with visual disability while they are touching. The following statements down below are the visually impaired perception through wall or room divider.

"While I am rubbing the space, I prefer to touch the floor. It is because the floors are usually smooth and nail-free. So I choose smoother surface." - Participant Didi, 06.00 pm, 3 February 2020.

"In my opinion, artistic is like two sides of a knife. One side is beneficial and valuable for people with vision. On the other side, which is for us who has vision disability, the more artistic building is made, the more difficult we approach. For me, aesthetic in architecture is minimalism. Ornaments are just a decoration and meaningless. "- Participant Ade, 10.00 am, 2 February 2020.

"When I was in Bali, I felt carved surface like in Bale-Bale, showed that I was not home because my house design is simple. Another indication was its structure like wood material in Sanggah (worship place)" - Participant Ade, 10.00 am, 2 February 2020.

Their limitations to experience visual graphic makes their tactile sense stronger. Those two participants explained their stories regarding unusual type of wall such as repetitive surface to contrast in natural surface such as water that flow through the wall. Those type of wall qualities will definitely enrich their experience while being at common building.

"While I was at the lounge, I felt like water were running through the wall, I like the sound of the water there." Participant Didi, 06.00 pm, 3 February 2020.
"The most impressed spatial experience was visiting Malang Regional Court yesterday. It was my first time entering the custody room and I was thrilled touching the bars, it feels connected to the room function." - Participant Fajar, 09.00 am, 2 February 2020.

\section{B. Apeture}

Pallasmaa (2005) discussed Significance of the Shadow that nowadays, light is merely a quantitative issue and overlook the window's significant role as a mediator between two boundaries; open and close, interiority and exteriority, private and public, shadow and light. Windows become the absence of the wall [12]. Many artworks apply window element in large scales. This unconsciously removes the intimacy of the building character itself, vanishes the traits of shadow and its qualities [12]. Proportion of window element in a large scale has forced us to build a public living space and diminish user's privacy, even though it would be much evoking if contemporary artwork spaces use spatial qualities with less intensity of light with uneven distribution [12]. Homogenous bright light feels decreasing the spatial experience [12].

That statement from Pallasmaa is relevant to the experience of the participant. Mostly they feel uncomfortable in a room with high level of brightness because it can damage their eyes. According to participant's responses, some of them are still able to identify the light intensity, mostly from low vision participants. But on the other hand, people with low vision also need lighting to find out the area around them. Even though shadow is not much giving impact for total blind participants, however further research is necessary because light quality also affects drop shadows and produces dark spots. This can deceive people with low vision because darker area often assumed as a hole or different level surface.

"I have issues with lighting contrast and dazzled when I was at the stage. It is because lighting stage that using beam of light often made my eyes burning. Other than that, everything is fine." - Participant Wawa, 07.00 am, 11 February 2020.

"I still have a little sight that can identify the light. Sometimes if distribution of light in a room is uneven, it can make me feel uncomfortable. For example, there is a brighter spot than the other part of a room, it can disturb my eyes and feel dazzled. Type of lights that bother me include flash on camera or direct spot light. For me, ideal room should have controlled lighting to adjust dim level." - Participant Egar, 07.00 am, 18 February 2020.

"I am not too affected but still can identify dark and bright." - Participant Fajar, 09.00 am, 2 February 2020.

"I personally prefer minimal lighting for room quality like at a café or lounge where it has dim light. I feel more comfortable while at dark place but for identification, I prefer brighter room. Overall I choose darker room because I find it difficult if it reversed." - Participant Didi, 06.00 pm, 3 February 2020.

"As a person who still has slight vision, shadows from buildings or trees might make me uncomfortable, but for a total-blind person, it doesn't affect at all." - Participant Egar, 07.00 am, 18 February 2020. 
The $6^{\text {th }}$ International Seminar on Science and Technology (ISST) 2020

July $25^{\text {th }} 2020$, Institut Teknologi Sepuluh Nopember, Surabaya, Indonesia

"For example, people often choose grey as a main flooring but use black as a signage; this could mislead me as a hole. Like at the mall, choosing guiding block colors with darker colors might be dangerous for people with loss vision." Participant Didi, 06.00 pm, 3 February 2020.

In addition, there are other obstacles caused by the use of wide openings. Not only does it affect people with low vision, it also affects people with totally blind. Ade said that using many apertures could become an obstacle for acoustic matter because too much noise will enter the building.

"For me, too many openings disturbed me, because a lot of noise make it less soundproofed." - Participant Ade, 10.00 am, 2 February 2020.

According to Downey interview on Vermeerch (2013), an architect with visual disability, stated that it made him focused on tactile sense against a building [16]. He explained that kind of experience mostly from places or building elements like a 'greeting' from a building; element design that can adjust to human body or the way user looking for a pathway, identifying a space [16]. Based on interviewing participants, they mostly recognize a building existence through door handle. Door handle become major facility in order to 'greet' people with visual impairment. One of the total blind participants, Ade, has an experience while reaching door handle. She has to follow rhythm of the wall and feel the contrast of the indented wall surface. Moreover, Egar thought that door panel could be an indicator of range level from one room to another. In addition, some of the participants technically answered how door handle should be safely designed. Using sliding door and avoiding glass material for building aperture are very significant for visual impaired people to access the building. One of low vision participants stated that large scale of wall application confused participants to access the door handle. This also support the statement from Pallasmaa that architecture with large openings, which involves lack of user's privacy, could become a barrier for visual impaired people to gain an access to enter the building.

"The best indicator to identify a space is physical element. For example a range from one room to another. Then physical appearance such as door panel, interior furniture, or the scale of the area itself (measuring the space range through door handle)." - Participant Egar, 07.00 am, 18 February 2020.

"Hinge door sometimes could be dangerous. If it opened then we cannot predict other visual impaired people from opposite direction. Not all of people with loss vision use upper hand technique so it will be dangerous if we collided." - Participant Didi, 06.00 pm, 3 February 2020.

"My obstacle while accessing a room is usually confused between glass door figures, which cannot identified between open and close, resembling big windows. This type of door is usually at convenience stores like Indomart, Alfamart, or rooms that using door like that." - Participant Wawa, 07.00 am, 11 February 2020.

\section{Railing and Giding Block}

Vermeech (2013) described Portuguese architect, Pereira, who recently lose his vision. He changed his perception in aesthetic from eyes to hand [16]. According to Pereira, shape and textures should be pleasing to touch before admirable to see [16]. The existence of guiding block with railing is very important for people with visual impairment. Similar to Nolen (2015) railing element is often installed on corridor as a path direction, where the railing is ended, they assume of entering a new space [11]. However, based on participants' answers, mostly explained their grievances towards guiding block and railings on general function buildings. They said that they could not properly utilized those two elements because there is lack of awareness from non-disabled people and incorrect installment. These are their perspective about guidling block and railings.

"While I was at a convention in Malaysia, it was at a church building. That building was accessible due to railing around the room. However, for mobilization, I avoided crowd because my cane could not move freely. The road itself was too crowded that they covered the guiding block and railing. In addition, in the crowded place, I felt like they stared at me." - Participant Ade, 10.00 am, 2 February 2020. "If I am in a building that is accessible, that means access that rely on technology. For example, I want a kind of simple guiding block, but the system is like an escalator. Because guiding block from usual tile could be misinterpreted." - Participant Didi, 06.00 pm, 3 February 2020.

"Broken guiding block could damage and obstruct my cane. Other than that, railing is helpful to find a path way." - Participatablent Fajar, 09.00 am, 2 February 2020.

\section{Furniture}

Visual aspect is the second indicator that could be perceived after tactile. Assuming that tactile work as an unconscious sense towards visual. In reality, our vision can feel the surface, contour, and edges; but through touch tactile sense, we unconsciously can distinguish comfort from experience. Through auditory system, we can also recall acoustic sound from uninhabited house and no furniture than clattered house, where sounds reverberated and muffled through furniture surfaces. Pallasmaa (2005) discussed Alvar Aalto project that involve all human sensory through his architecture artwork [12]. His suggestions regarding sensory aspects towards furniture design is showing apprehension in design application in general [12]. Designing furniture should avoid shapes that reflect glare, produce undesirable sounds, acoustic wise, and prioritize safety [12]. Through participant's answers, they have personal views towards each element of furniture. The existence of furniture is connected to echo, mobilization, safety while touching surfaces, and range level in a room. One of total blind participants is able to acknowledge if a room is furnished or vacant through the echo.

"Sometimes I can recognize if a room is not furnished yet, I know about echo in a room. When there are many objects in a room, then it lessen the intensity of moving sounds. "Participant Ade, 10.00 am, 2 February 2020.

As stated by Alvar Aalto in Pallasmaa, furniture placement should now harm the users [12]. This statement supports responses from participants which arranging furniture should 
The $6^{\text {th }}$ International Seminar on Science and Technology (ISST) 2020

July $25^{\text {th }}$ 2020, Institut Teknologi Sepuluh Nopember, Surabaya, Indonesia

consider symmetrical aspects to avoid any harm. In addition, furniture could measure distance between rooms.

"Sometimes furniture can interfere mobilization, twist and turn like a hotel room I visited last time. The sink was stand out unsymmetrical. I thought the shape of the room was square but furniture arrangement, which supposed to create artistic look, turned out unimaginable for us with visual disability. For me, artistic is like two sides of a knife. One side is beneficial and valuable for people with vision. On the other side, which is for us who has vision disability, the more artistic building is made, the more difficult we approach." Participant Ade, 10.00 am, 2 February 2020.

"There are rooms with many furniture arrangements like chairs in several spots that make me confused which way should I take." - Participant Wawa, 07.00 am, 11 February 2020.

"For example, a distance between rooms. Then physical characteristic of a room like furniture." - Participant Egar, 07.00 am, 18 February 2020.

\section{CONCLUSION}

As implied on Clark analysis (2005), that circulation pattern is created from connection between rooms [1]. Those patterns suggest concentric, linier, and grid. The connection of circulation and its space can also show condition of privacy and correlation [1]. It certainly cannot be juxtaposed with finding results from visually impaired perception towards architecture. They rely perceptual other than visual to find a pathway and identify a space rather than acknowledging type of circulation. Hearing is one of sensory system that is sensitive for them. Therefore, through noise (olfactory), they can estimate quality of a room. People with visual impairment need high concentration on doing works using their hearing and tactile senses that they need a silent space. On the other hand, they need a crowded room to interact. According to this statement, it concludes that visual impaired people pay attention to noise hierarchy for their comfort while doing activities.

Based on those discussions, it conclude that visually impaired participants have their preferable definition towards interpreting the aesthetic of architecture. It should not only be accessible and comfortable, but also give a new sensory experience for people with visual disability. Building elements that are able to communicate with its user not merely through visual aspects, but through auditory, aural, and haptic senses. Building elements has indicator roles as spatial measurement and signage through the pathway for mobilization. From those five elements of architecture, element of opening and wall become the most significant element because it affects the quality of the room for people with loss of vision. These elements are influential to noise, echo, and light intensity that low vision people still catch. Vision disability recognize architectural principles such as light and temperature contrast through apertures, rhythm of texture from wall, balance of texture surface from furniture, and noise hierarchy through window and wall. As for suggestions for architect, designer, and legislator to involve those design principles to create inclusive environment, importantly on public buildings and facilities.

\section{ACKNOWLEDGMENTS}

This paper is a part of master's thesis research and supported in part by Master Thesis Research Grant Year 2020 funded by Deputi Bidang Penguatan Riset dan Pengembangan, Kementerian Riset dan Teknologi/ Badan Riset dan Inovasi Nasional.

\section{REFERENCES}

[1] Clark R. H. and Pause M, Precedents in architecture: Hoboken, N.J: Wiley, 2005.

[2] Fondation de Paris, The museums without barriers: A new deals for disable. London: Routledge, 1991.

[3] Giancarli, Share Perception: Utilizing the Auditory and Haptic senses in Design for Varying Visual Abilities. Unpublished Research and thesis Project. Wentworth Institute of Technology, Architecture Department, US, 2013.

[4] Grabow, S, Frozen music: the bridge between art and science". In Farmer, B., \& Louw, H. (eds.) Companion to Contemporary Architectural Thought. London:Routledge, 1993.

[5] Hill, M, H, Bound to the Environment: Towards A Phenomenology of Sightlessness dalam Seamon, David \& Mugerauer, Robert. (Ed) Dwelling, Place and Environment Towards A Phenomenology of Person and World: Martinus Nijhoff Publishers, Dordrecht, 1985.

[6] Jenkins G R, Yuen H K, Experience of Multisensory Environments in Public Space among People with Visual Impairment, Department of Occupational Therapy, School of Health Professions, University of Alabama at Birmingham, Birmingham, AL 35294, USA; E-Mails: jenkinsg@uab.edu (G.R.J.); lvogtle@uab.edu (L.K.V.), July. 2015.

[7] Joy Monice Malnar, Frank Vodvarka (2004) Sensory Design. Minneapolis. University of Minnesota Press

[8] Koupaei S E, Borazjani V N, Safian M J, 2018, Phenomenology; A Methodology for Understanding Traditional Architecture, The Scientic Journal of NAZAR research center $(\mathrm{Nrc})$ for Art, Architecture \& Urbanism

[9] Majerova, The Person in a Situation of Visual Impairment and its Perception and Imagination from the Qualitative Viewpoint. Proceeding of 7th International Conference on Intercultural Education "Education, Health and ICT for a Transcultural World", EDUHEM 2016, 15-17 June 2016.

[10] Mcintyre L J, Hanson V L, Buildings and Users with Visual Impairment: Uncovering Factors for Accessibility using BIT-Kit, School of Computing University of Dundee Dundee, DD1 4HN, Scotland lesleymcintyre@computing.dundee.ac.uk, Golisano College of Computing and Information Sciences, Rochester Institute of Technology20 Lomb Memorial DriveRochester, NY USA 14623 vlh@acm.org. Oct. 2014.

[11] Nolen, Architecture without vision. Unpublished Master Thesis of Architecture. School of Architecture, Planning, \& Preservation. Faculty of the Graduate School of the University of Maryland, College Park, 2015.

[12] Pallasmaa J, The eyes of the skin - Architecture and the senses, WileyAcademy, United Kingdom, pp. 46, 192, 2005.

[13] Rapoport, Amos, The Meaning of the Built Environment, SAGE Publications, India, 1982.

[14] Tran D, Phenomenology method of making a place, University of Architecture Ho Chi Minh City, 196 Pasteur st., Dist.3, Ho Chi Minh City, Vietnam, MATEC Web of Conferences 193, 04021, 2018.

[15] Vermeersch P W And Heylighen A, Blindness and multi-sensoriality in architecture: the case of Carlos Mourão Pereira, ARCC/EAAE 2010 international conference on architectural research, edition 7 , Washington DC, 2010.

[16] Vermeersch Pw, Less Vision, More Senses Towards A More Multisensory Design Approach in Architecture, Dissertation presented in partial fulfillment of the requirements for the degree of Doctor of Engineering Sciences: Architecture, January.2013. 